\title{
Lung cancer survival in Norway, 1997-2011: from nihilism to optimism
}

\author{
Yngvar Nilssen ${ }^{1}$, Trond Eirik Strand ${ }^{1}$, Lars Fjellbirkeland ${ }^{2,3}$, Kristian Bartnes $^{4,5}$ \\ and Bjørn Møller ${ }^{1}$ \\ Affiliations: \\ ${ }^{1}$ Dept of Registration, Cancer Registry of Norway, Oslo, Norway. \\ ${ }^{2}$ Dept of Respiratory Medicine, Oslo University Hospital, Oslo, Norway. \\ ${ }^{3}$ Institute of Clinical Medicine, Faculty of Medicine, University of Oslo, Oslo, Norway. \\ ${ }^{4}$ Division of Cardiothoracic and Respiratory Medicine, University Hospital North Norway, Troms $\emptyset$, Norway. \\ ${ }^{5}$ Institute of Clinical Medicine, UiT - The Arctic University of Norway, Tromsø, Norway. \\ Correspondence: \\ Yngvar Nilssen, Dept of Registration, Cancer Registry of Norway, Oslo, Norway. \\ E-mail: yngvar.nilssenakreftregisteret.no
}

ABSTRACT We examine changes in survival and patient-, tumour- and treatment-related factors among resected and nonresected lung cancer patients, and identify subgroups with the largest and smallest survival improvements.

National population-based data from the Cancer Registry of Norway, Statistics Norway and the Norwegian Patient Register were linked for lung cancer patients diagnosed during 1997-2011. The 1- and 5 -year relative survival were estimated, and Cox proportional hazard regression, adjusted for selected patient characteristics, was used to assess prognostic factors for survival in lung cancer patients overall and stratified by resection status.

We identified 34157 patients with lung cancer. The proportion of histological diagnoses accompanied by molecular genetics testing increased from $0 \%$ to $26 \%$, while those accompanied by immunohistochemistry increased from $8 \%$ to $26 \%$. The 1-year relative survival among nonresected and resected patients increased from $21.7 \%$ to $34.2 \%$ and $75.4 \%$ to $91.5 \%$, respectively. The improved survival remained significant after adjustment for age, sex, stage and histology. The largest improvements in survival occurred among resected and adenocarcinoma patients, while patients $\geqslant 80$ years experienced the smallest increase.

Lung cancer survival has increased considerably in Norway. The explanation is probably multifactorial, including improved attitude towards diagnostic work-up and treatment, and more accurate diagnostic testing that allows for improved selection for resection and improved treatment options.

@ERSpublications

Lung cancer survival in Norway has improved due to improved attention towards diagnostic work-up and treatment http://ow.ly/S5L4j

This article has been revised according to the correction published in the April 2016 issue of the European Respiratory Journal.

This article has supplementary material available from erj.ersjournals.com

Received: April 252015 | Accepted after revision: Aug 12 2015 | First published online: Nov 052015

Support statement: This study was funded by the South-Eastern Norway Regional Health Authority. Funding information for this article has been deposited with FundRef.

Conflict of interest: Disclosures can be found alongside the online version of this article at erj.ersjournals.com

Copyright @ERS 2016 


\section{Introduction}

Lung cancer survival in Norway was low in the 1960s and remained so until the new millennium, with 1and 5-year relative survival at around $30 \%$ and $10 \%$, respectively, for both sexes combined [1]. This pattern is similar to that observed in other countries with comparable health systems and wealth, and 5-year age-standardized relative survival in Norway has been shown to be equal to the European mean $[2,3]$.

There are indications that diagnostic accuracy in lung cancer and lung cancer survival have improved recently [2, 4-6]. A favourable trend was seen in Norway in 2006-2007 compared with earlier periods, with 1-year survival reaching $81 \%$ among resected lung cancer patients [6]. However, most studies on prognosis and prognostic factors for lung cancer have been based on populations with advanced-stage cancers or resected lung cancers, or they were based on hospital data (nonpopulation based) [7-9]. As the prognosis of lung cancer differs greatly among resected and nonresected patients, it is important to distinguish between these groups. A few population-based studies have considered lung cancer patients overall, regardless of resection status, but focusing on trends in incidence or prognoses associated with different treatments $[10,11]$.

Lung cancer patients have suffered stigmatisation and a nihilistic attitude towards diagnostic work-up and treatment on the part of healthcare professionals, which was indicated by the finding that resection, generally considered a prerequisite for cure, was underutilized in 1995-1998 in Norway [12, 13]. Historically, it has been surmised that lung cancer research was underfunded due to the disease's poor prognosis. However, in the early 2000s there were increased efforts to improve all aspects of lung cancer care $[6,14,15]$.

The aim of the present study was to examine changes in survival and patient-, tumour- and treatment-related factors affecting survival among resected and nonresected lung cancer patients. We also sought to identify subgroups of age, sex, socioeconomic status, histology and treatment with the largest and smallest improvement in survival over the last decade.

\section{Methods}

Cancer Registry of Norway

The Cancer Registry of Norway (CRN) is a directive from the country's Ministry of Health. The CRN has been collecting notifications on cancer occurrence for the Norwegian population since 1953. It is estimated that the quality, comparability, completeness, validity and timeliness of the CRN data are high, with $96.9 \%$ estimated completeness for lung cancer. Historically, these notifications have been sent in paper format, which must then be coded electronically in-house by the CRN. The CRN also receives death certificates from the Cause of Death Registry and is matched monthly against the National Population Register to ensure that vital status (death or emigration) is updated [16].

\section{Data sources}

The personal identification number allows information on all Norwegian citizens to be linked across institutions and databases. Population-based data from the CRN were used to identify all patients diagnosed with malignant neoplasm of bronchus and lung (International Classification of Diseases, Revision 10, code C34) between January 1, 1997 and December 31, 2011 in Norway. The CRN receives patient-identifiable data annually from all radiotherapy centres in Norway. Only information about the first series of radiotherapy was included in the current study. The CRN also contains comprehensive data for all resected patients. Information on socioeconomic status, as measured by highest achieved education and income level the year before lung cancer diagnosis, was obtained from Statistics Norway. Information on comorbidity during the year prior to diagnosis was taken from the Norwegian Patient Register, but it was only available for patients diagnosed after January 1, 2009, as person-identifiable data is only available in the register from January 2008 onwards.

\section{Classification of variables}

Education level was categorised as low (lower secondary school), intermediate (upper secondary school) or high (university or similar). The cut-offs for income level were set at the 33rd and 66th percentile, were redefined every year, and were stratified by sex. Stage at the time of diagnosis was categorised as localised, regional or metastasis according to the condensed tumour-node-metastasis (TNM) status [17]. The CRN recoded all cancer cases after the Union for International Cancer Control standards version 7 based on individual TNM descriptors [18]. TNM status was not available for nonresected lung cancer patients. This will become available in the Norwegian Lung Cancer Registry, which resides within the CRN, which is collecting data on lung cancer patients diagnosed from 2013 onwards. Stage in resected patients was coded according to pathological TNM status (pTNM) [18]. Histology was classified according to the classification of the World Health Organization [19]. Comorbidity was measured using a version of the Charlson Comorbidity Index (CCI) adapted to national patient registers, and categorised as no hospital admissions $(\mathrm{CCI}=-1)$, low $(\mathrm{CCI}=0)$, intermediate $(\mathrm{CCI}=1,2)$ and high $(\mathrm{CCI} \geqslant 3)[20]$. Doctor-reported 
smoking status was categorised as never, current or former. Treatment intention for radiotherapy was categorised as radical (including curative, local control and prophylactic) or palliative [21]. However, no information was available about whether the radiotherapy given was targeted at the primary lung tumour or elsewhere, e.g. prophylactic brain radiation. When treatment intention was missing (6\% of patients), it was assigned based on the radiotherapy dose applied, in accordance with the national guidelines available during the study period [22]. Small cell carcinoma patients receiving doses of $\geqslant 42$ and $<42$ Gy were categorised as radical and palliative, respectively. Nonsmall cell carcinoma patients were categorised as radical if they received doses of $\geqslant 50 \mathrm{~Gy}$ in addition to surgery or $\geqslant 60 \mathrm{~Gy}$ without surgery, otherwise radiotherapy was classified as palliative [21, 22]. Resection and radiotherapy were included as time-dependent variables in the model, i.e. all patients start follow-up as untreated where they contribute time-at-risk to the untreated group, but at the date of treatment, patients contribute time-at-risk to the treatment group. Patients who underwent exploratory thoracotomy were categorised as nonresected, while patients receiving upper-, middle- or lower-lobectomy, bilobectomy, pneumonectomy, or sublobar/ segmental resections were categorised as resected. Date of diagnosis was coded as the first occurrence out of the date given by the clinician, date of the first histological verification and date of death. Until 2003, date of diagnosis was coded as the first day in the month, while after 2003, the CRN started coding the exact date. To obtain consistency, all dates of diagnoses were set to the first of the corresponding month.

\section{Study sample}

In total, 35132 patients were diagnosed with lung cancer in the CRN in 1997-2011. Of these, 41 were excluded due to registration errors and 16 due to surgery abroad. 222 patients were diagnosed at autopsy, 623 were registered based on death certificate alone, and 73 were registered with other specified histology (81\% of which were sarcoma) and were also excluded. This left a final study sample of 34157 lung cancer patients (online supplementary figure S1).

\section{Statistical analysis}

Multiple imputation was used to handle incomplete data on education, income, stage, histology, laterality, tumour size, resection procedure and smoking [23]. Multiple imputation is a statistical method that uses available data to model the likely distribution of missing data. We ran the imputation model 30 times and combined the results using Rubin's rule [23]. This was performed using the mi impute chained command in Stata 13.1 [24].

The 1- and 5-year relative survival were estimated using the lifetable method and calculated using inverse probability weighting as proposed by PoHAR-PERme [25]. Each patient was assigned a weight corresponding to 1-the cumulative probability of dying from all other causes. These weights are estimated using a national lifetable stratified by age, sex and calendar time measured by yearly intervals. In order to use the most recent data, the hybrid method was applied to estimate 5-year relative survival [26]. Univariate and multivariate analysis for 1-year survival, adjusted for diagnostic period, age, sex, socioeconomic status, stage, histology, topography, laterality, comorbidity and treatment-specific variables, was performed using Cox regression to identify possible risk factors.

The 1-year survival analyses were performed in three groups: 1) all lung cancer patients, 2) nonresected patients and 3) resected patients. For the estimations of relative survival, follow-up time in the three groups started from date of diagnosis, while in the regression analyses, group 3 was followed from date of surgery. Group 2 patients who either received resection alone or who received adjuvant radiotherapy were censored at date of surgery and did not contribute follow-up time post-resection. Therefore, the definition of the end of follow-up is defined as 1 year after the date of diagnosis, surgery, death or emigration, whichever came first. As group 3 patients were followed from date of diagnosis and not from date of surgery, an immortal time bias was introduced. However, we believe the bias to be small, partly due to the short time between diagnosis and surgery, and partly due to the high probability of survival by the candidates considered for surgery, during the same period. In the regression analysis this bias is handled by including surgery as a time-dependent variable. Data regarding pTNM, resection procedure and tumour size were available for group 3 and included in the regression model. We performed the same analyses using complete case data; however, similar results were obtained. In order to reveal temporal survival trends within subgroups, we compared survival among patients diagnosed in the first (1997-2003) and those diagnosed in the second (2004-2011) half of the study period using a multivariate Cox regression model adjusting for available explanatory variables.

In two subgroup analyses focusing on comorbidity and smoking, 1-year survival was calculated using a multivariate Cox regression model in a similar manner as described above. When analysing comorbidity we used the period 2009-2011, while for smoking we used 2004-2010. p-values $<0.05$ were considered significant. 


\section{Results}

Demographic and clinical characteristics of the study sample are given in table 1 . There were $6160(18.0 \%)$ resected patients (table 1). Median time from lung cancer diagnosis to death among resected and nonresected patients was 39 and 5 months, respectively.

The 1- and 5-year relative survival for all lung cancer patients increased from $35.4 \%$ to $47.6 \%$ and $11.6 \%$ to $17.5 \%$, respectively, during the study period (figure 1). The 1- and 5-year relative survival among nonresected patients increased from $28.4 \%$ to $37.0 \%$ and $3.6 \%$ to $6.3 \%$, respectively. Corresponding figures among resected patients were $77.2 \%$ to $93.3 \%$ and $47.0 \%$ to $62.6 \%$, respectively (figure 2 ). For both resected and nonresected patients the hazard ratio for death up to 2 years after resection/diagnosis was consistently lower in 2004-2011 compared with 1997-2003, varying from 0.50 (95\% CI $0.37-0.68$ ) to 0.71 (95\% CI $0.62-0.82$ ) for resected and from 0.75 (95\% CI $0.70-0.81)$ to 0.88 (95\% CI $0.83-0.94$ ) for nonresected patients (figure 3). Survival during the third year after diagnosis was similar in 1997-2003 and 2004-2011 among both resected and nonresected (figure 3).

The median time from diagnosis to resection increased from 26 days in 2005 to 36 days in 2008 (figure 4). Resection rates varied between $16.1 \%$ and $20.8 \%$ during the study period, but no clear trend was observed (figure 4). Univariate and multivariate analyses stratified by resection status showed a steady increase in 1 -year survival in resected and nonresected patients, although the improvement was largest among resected patients (table 2). A significant increased mortality by stage was observed in all patients (regional versus local: hazard ratio 2.09, 95\% CI 1.96-2.23; metastasis versus local: hazard ratio 4.97, 95\% CI 4.68-5.28). However, after stratification by resection status, most of the effect disappeared. The univariate analysis of all patients showed that risk of death within 1 year of diagnosis was 1.4 times higher among patients with small cell carcinoma than those with squamous cell carcinoma. However, the multivariate analysis did not substantiate this difference. The observed effect was reduced mostly by the inclusion of stage in the model (data not shown). Income and education level persisted as independent factors (table 2).

For all major histological types, and most profoundly for adenocarcinoma, 1-year survival improved. Even though there have been limited advances in management for small cell lung cancer patients, this group has also experienced an improvement in survival. Patients $\geqslant 80$ years of age experienced the smallest improvement in survival (hazard ratio $0.87,95 \%$ CI $0.82-0.93$ ) (table 3 ). When stratifying our analysis into nonsmall cell lung cancer and small cell lung cancer patient groups, the results with respect to the level of the risk factors and survival improvements within the other explanatory variables differed by $<10 \%$ from the overall results (data not shown).

Between $20 \%$ and $25 \%$ of lung cancer patients were diagnosed without histological examination. From 2009 onwards, a steep increase was observed in histological diagnoses accompanied by molecular genetics testing, likely related to the implementation of epidermal growth factor receptor (EGFR) testing. An increase in the use of immunohistochemistry was also observed. Hence the proportion of diagnoses based on histology alone decreased (figure 5). Online supplementary figure 2 shows an increasing proportion of adenocarcinoma patients among lung cancer patients over time. Part of this increase can be explained by general diagnostic improvements, and more specifically improvements in immunohistochemistry and EGFR testing (data not shown).

\section{Comorbidity and smoking}

Overall, more severe comorbidity and being a current smoker were identified as negative prognostic factors in all three subanalyses (table 2). However, including comorbidity and smoking information into the analysis explained some, but not all of the effect of education and income level among resected and nonresected patients (data not shown). The other explanatory variables were only marginally affected after adjustment for comorbidity and smoking (data not shown).

\section{Discussion}

The 1- and 5-year relative survival increased significantly among resected and nonresected lung cancer patients between 1997 and 2011. The improvement was most profound among resected patients and those with adenocarcinoma, and least noticeable for patients $\geqslant 80$ years of age. The overall improvement persisted after adjustment for available explanatory variables.

The observed increase in 5-year relative survival in our study is in line with the estimates that have been reported by the international CONCORD-2 study, which included data from 279 population-based registries [27]. Our study additionally observed an improved survival for all stages through the study period. This corresponds with the results reported in a Dutch study, which showed that stage IV nonsmall cell lung cancer patients experienced increased survival, attributable to an increased use of chemotherapy [28]. 
TABLE 1 Selected characteristics of patients diagnosed with lung cancer in the period 1997-2011 in Norway

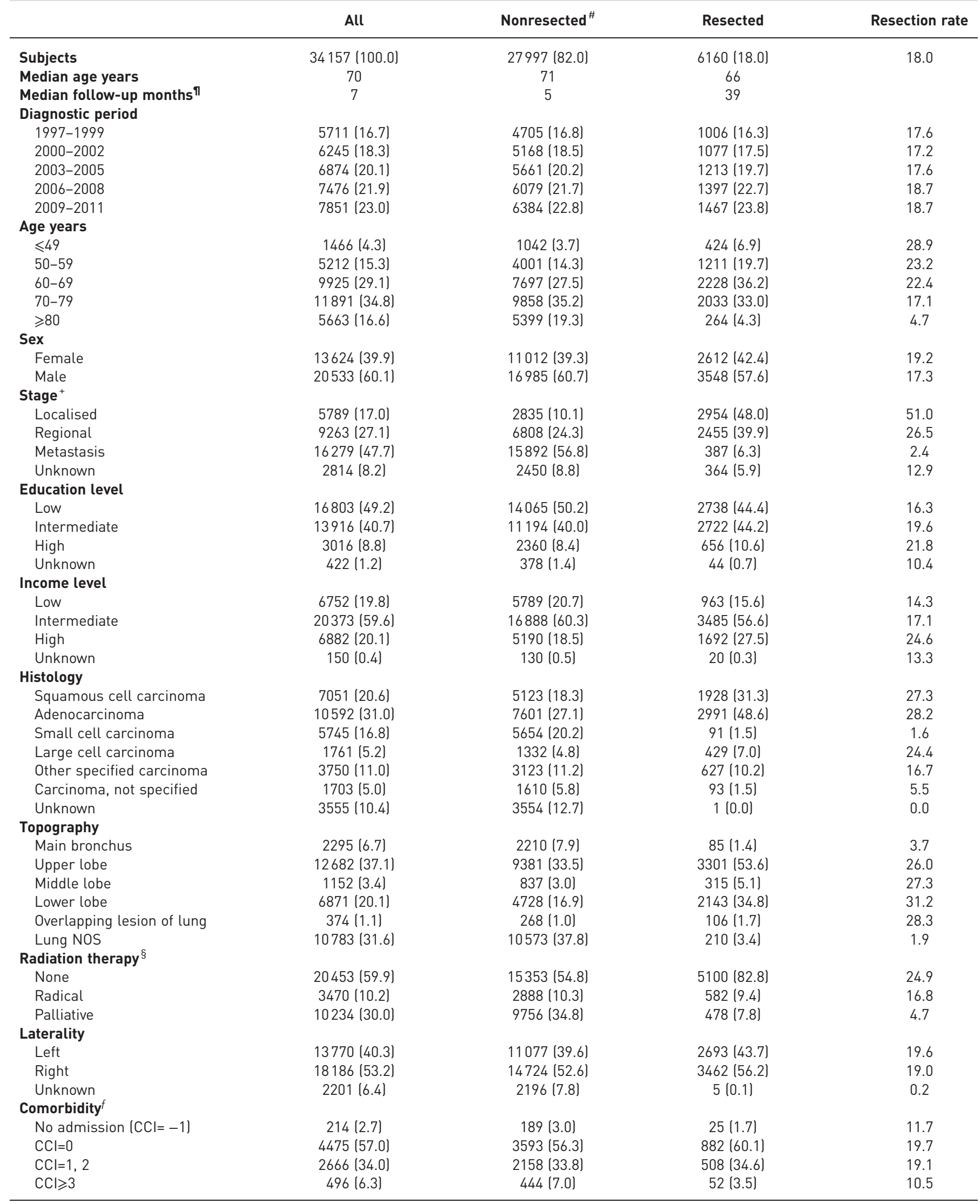


TABLE 1 Continued

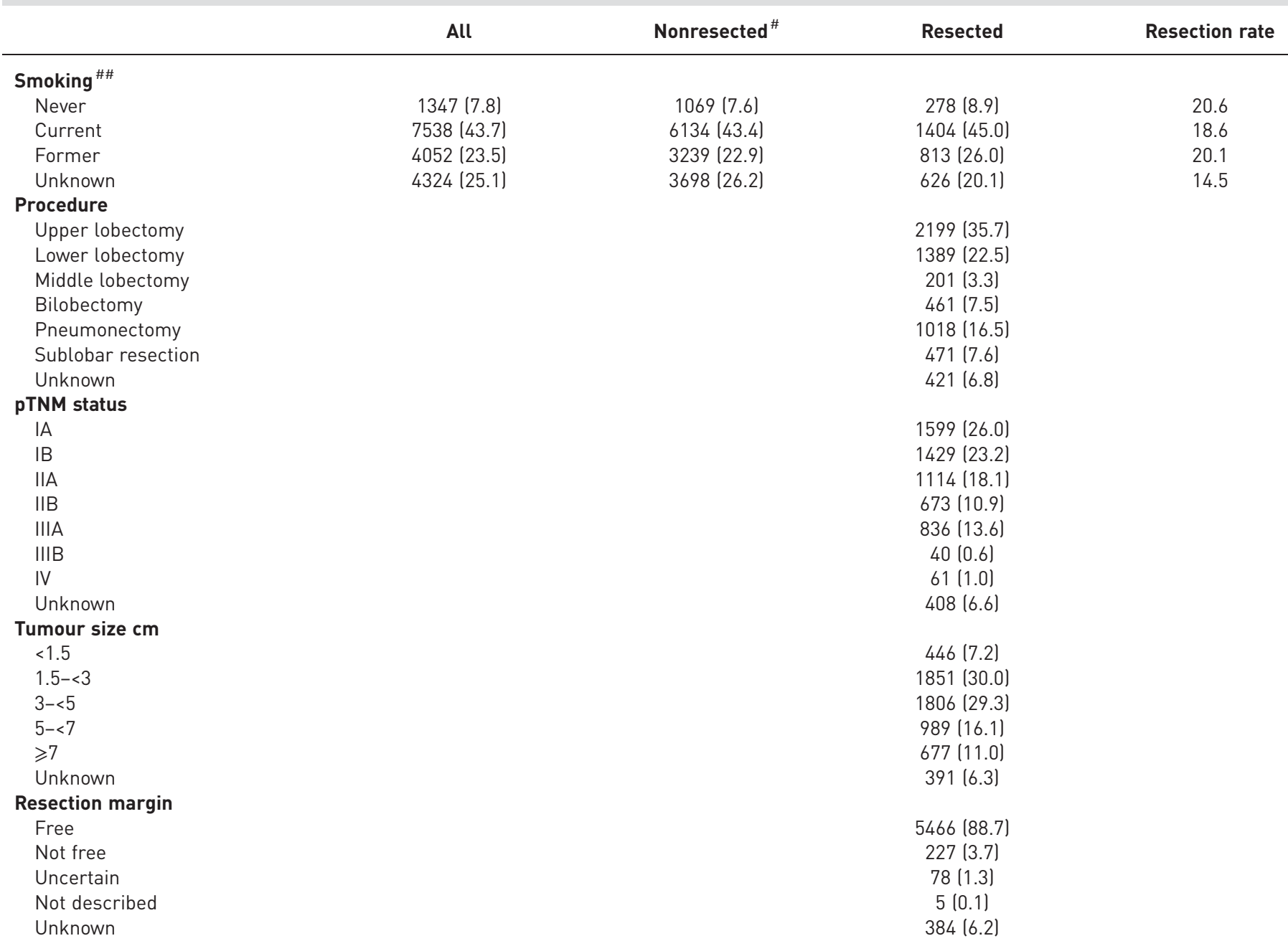

Data are presented as $\mathrm{n}(\%)$ or \%, unless otherwise stated. NOS: not otherwise specified; CCI: Charlson Comorbidity Index; pTNM: pathological tumour-node-metastasis. \#: includes patients undergoing explorative thoracotomy; " : median number of months between diagnosis and end of follow-up; ${ }^{+}$: see [17]; ${ }^{\S}$ : treatment given within 1 year of diagnosis; ${ }^{f}$ : available for patients diagnosed in 2009-2011; ${ }^{\# \#}$ : available for patients diagnosed in 2004-2010.

In 1987, the Norwegian Lung Cancer Group was founded to raise awareness and promote lung cancer care. In 2000, they released the first version of the National Guidelines for Lung Cancer Treatment; an updated version came in 2010 to reflect new developments in treatment [22]. In November 2008, the first lung cancer patients association was founded in Norway with the intention to increase the focus on this patient group, to inform and support patients and their relatives, and to serve as a link between patients, relatives, and the government. Many historical changes have taken place in lung cancer care in Norway during the study period and these can be divided into two categories: diagnosis- and treatment-related. The diagnosis-related changes include increased ad hoc screening, improved immunohistochemistry, introduction of positron emission tomography (PET) scan and better molecular genetics, while the treatment-related changes included the introduction and updated versions of the national guidelines, introduction of multidisciplinary team meetings, centralisation, introduction of stereotactic radiotherapy and adjuvant treatment, the activities of the Norwegian Lung Cancer Group, and the formation of the Patient Association (figure 1) [29].

The proportion of patients diagnosed by histological examination alone decreased from $68 \%$ to $30 \%$ in 1997-2011, which is to be expected when more advanced methods are available. Immunohistochemistry allows pathologists to determine histological subgroups even in small biopsies and cytology samples, which is of paramount importance when choosing appropriate treatment. We see the increased use of immunohistochemistry as a sign of increased diagnostic focus on lung cancer patients. Personalised 


\section{Events}

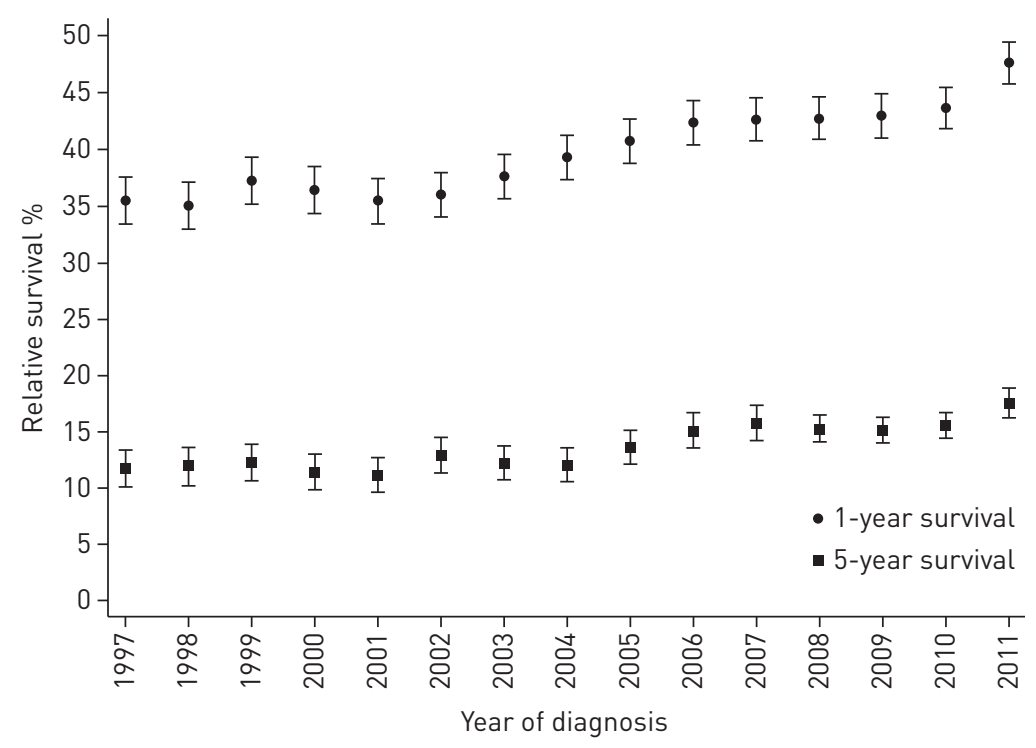

Start of NLCG

Ad hoc screening

Immunohistochemistry

Centralisation

First National Guideline

Publication of quality indicators

Adjuvant treatment ${ }^{\#}$

Multidisciplinary team meetings

PET scan

Stereotactic radiotherapy

Patient Association

Second National Guidelines

FIGURE 1 The 1- and 5-year relative survival (with 95\% confidence interval) for all lung cancer patients diagnosed in Norway ( $n=34157$ ), as well as events that have changed lung cancer care in Norway with year of implementation from 1997 to 2011. Follow-up time is defined as time from diagnosis. NLCG: Norwegian Lung Cancer Group; PET: positron emission tomography. " : platinum-based adjuvant chemotherapy after resection.

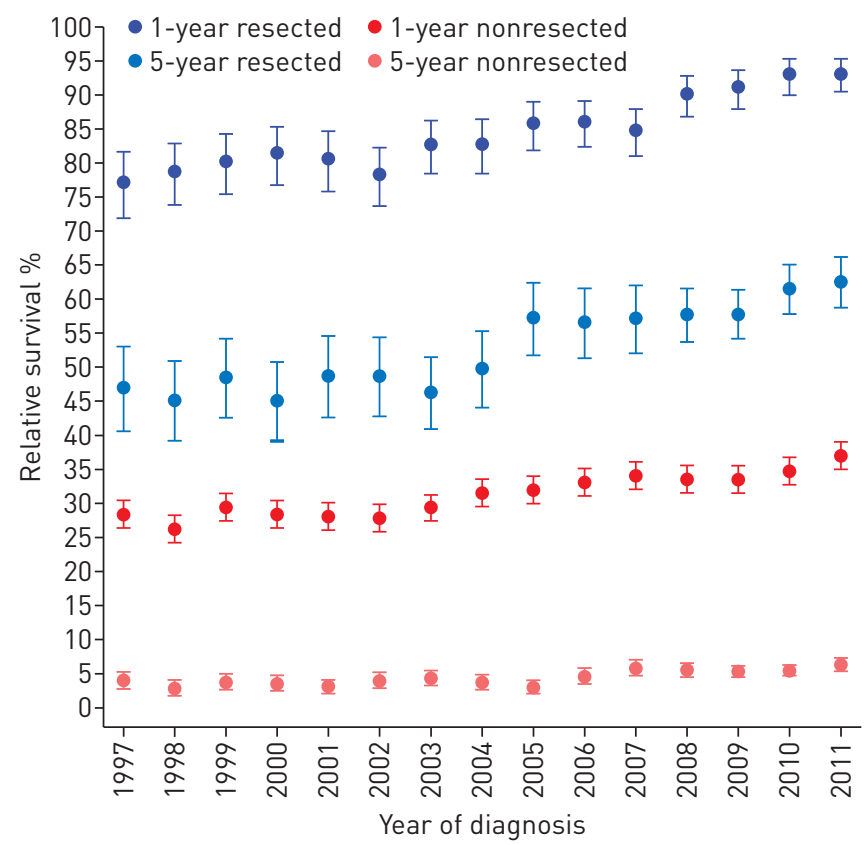

FIGURE 2 The 1 - and 5-year relative survival (with 95\% confidence interval) for resected and nonresected lung cancer patients diagnosed in Norway ( $n=34$ 157), 1997-2011. Follow-up time is defined as time from diagnosis. 


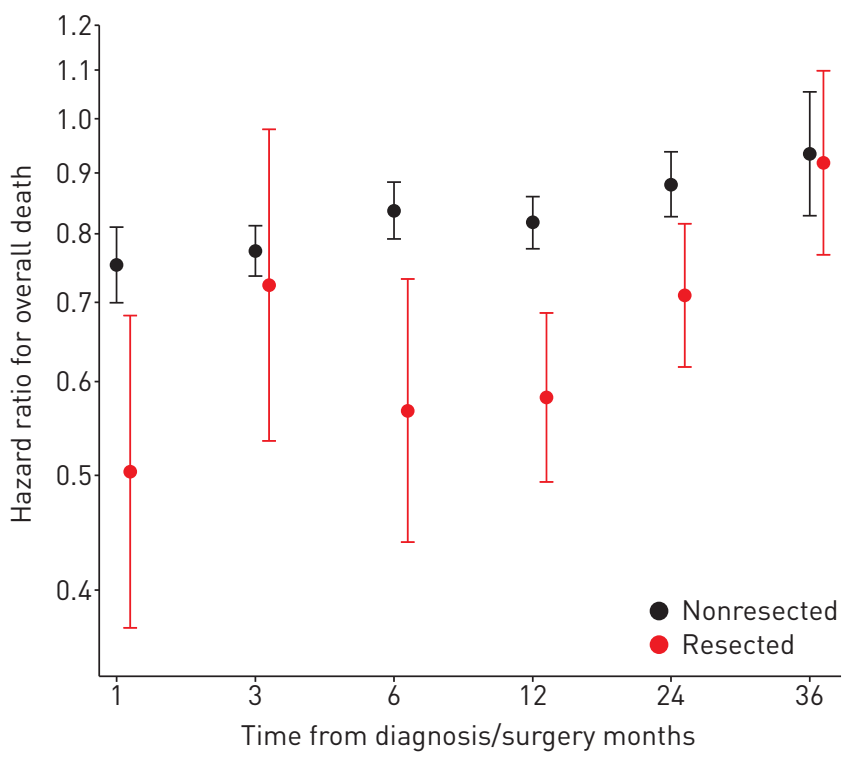

FIGURE 3 Change in hazard ratios for death after lung cancer resection/ diagnosis among resected/ nonresected lung cancer patients in Norway diagnosed in 1997-2002 (reference) and 2003-2011 ( $\mathrm{n}=34$ 157).

medicine in the form of tyrosine kinase inhibitors was rarely seen in our study sample. Testing for specific mutations, i.e. EGFR, started in 2010 and was routine by the end of 2011. In 2009, MoK et al. [30] reported extended progression-free survival among EGFR-positive patients treated with gefitinib compared with conventional chemotherapy. Hence, the increase in survival observed in our study from 2010 to 2011 may be partly attributable to increased EGFR-driven therapy. EGFR is more often expressed in adenocarcinomas than squamous cell carcinomas, which might explain why the largest improvement in survival was observed among adenocarcinoma patients [31, 32].

In general, more ad hoc screening is taking place in Norwegian hospitals through greater use of computer tomography (CT). A recent report showed that the number CT scans of the thorax performed in Norway more than doubled from 2002 to 2008 [33]. This may have led to earlier diagnosis and a shift toward more localised stage at diagnosis, but has probably been offset by the increase in advanced-stage disease due to more and better examination of possible metastases (online supplementary figure S2). PET-CT was implemented in Norway after 2007 and has a higher sensitivity to detect metastases than regular CT [34]. Hence, doctors are expected to assign more accurate diagnoses, but they also aid in selecting appropriate treatment. Even though

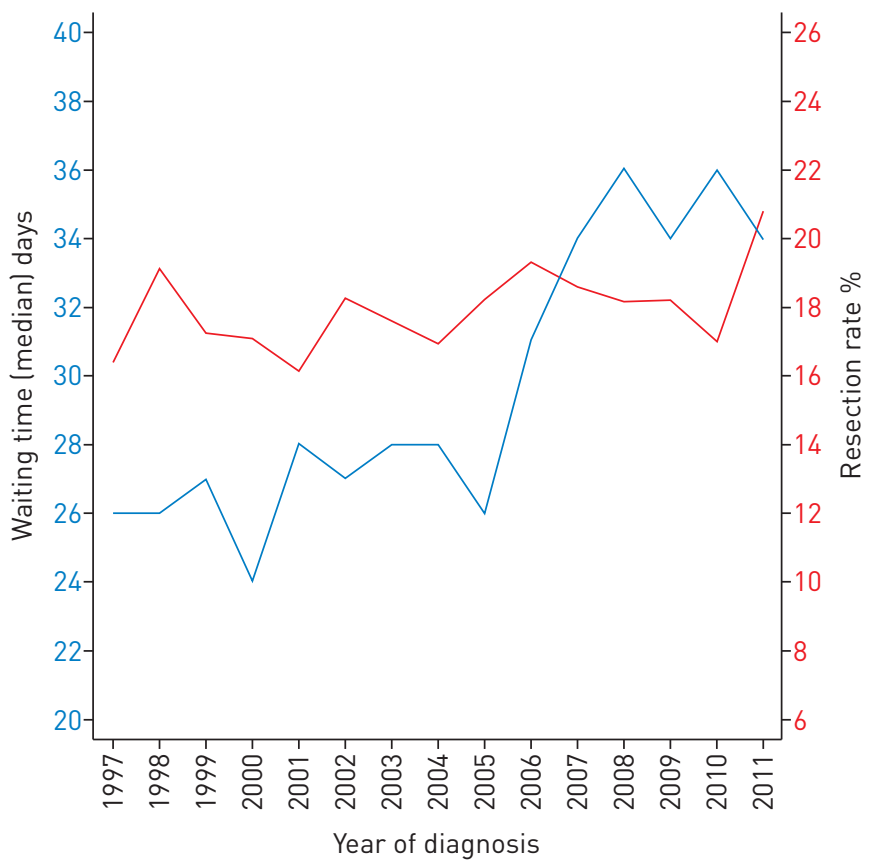

FIGURE 4 Median waiting times from diagnosis to resection and resection rates among Norwegian lung cancer patients, 1997-2011 ( $n=34$ 157). 
TABLE 2 Univariate and multivariate Cox proportional regression analysis for all patients, nonresected patients and resected lung cancer patients diagnosed in 1997-2011 in Norway

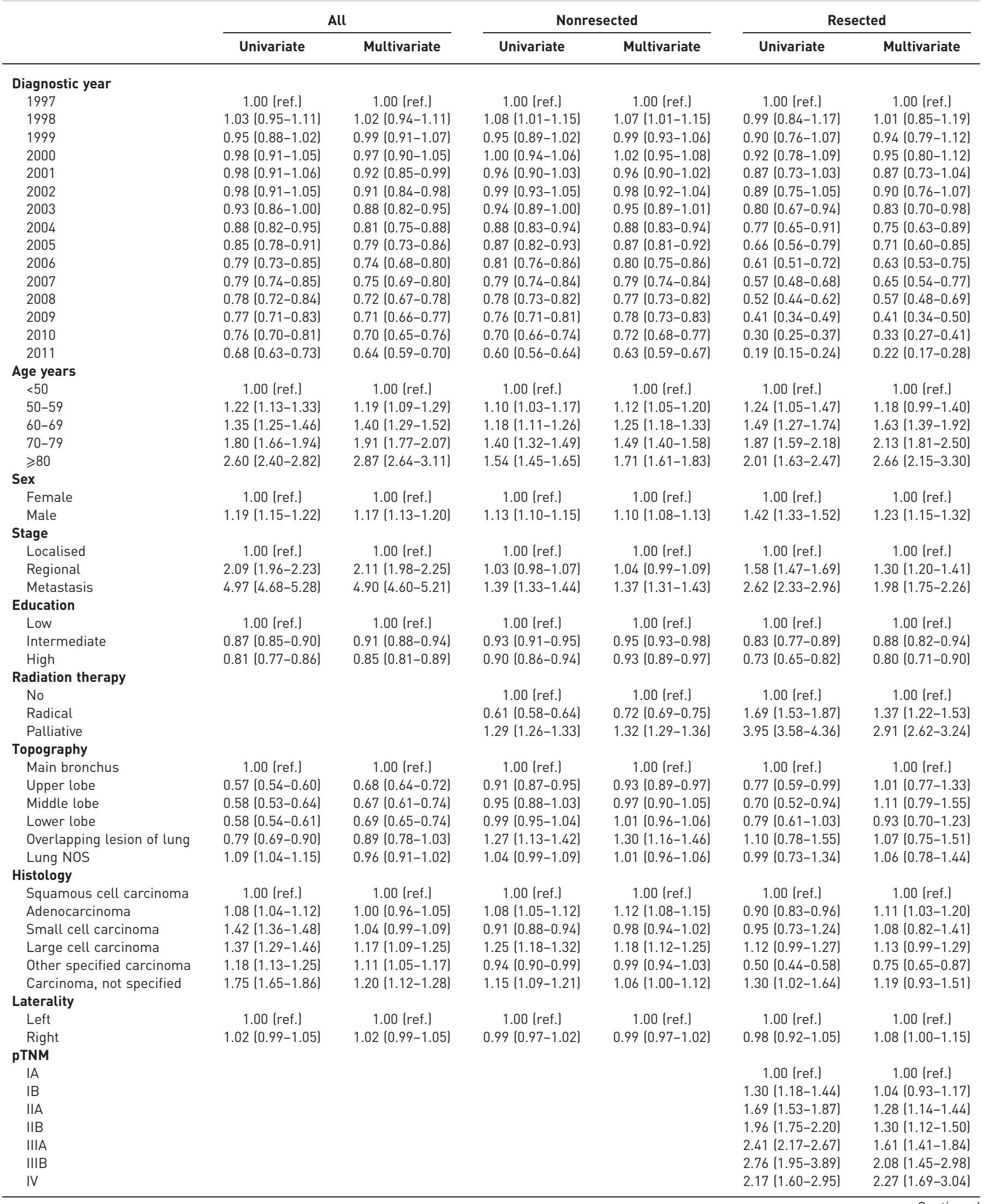


TABLE 2 Continued

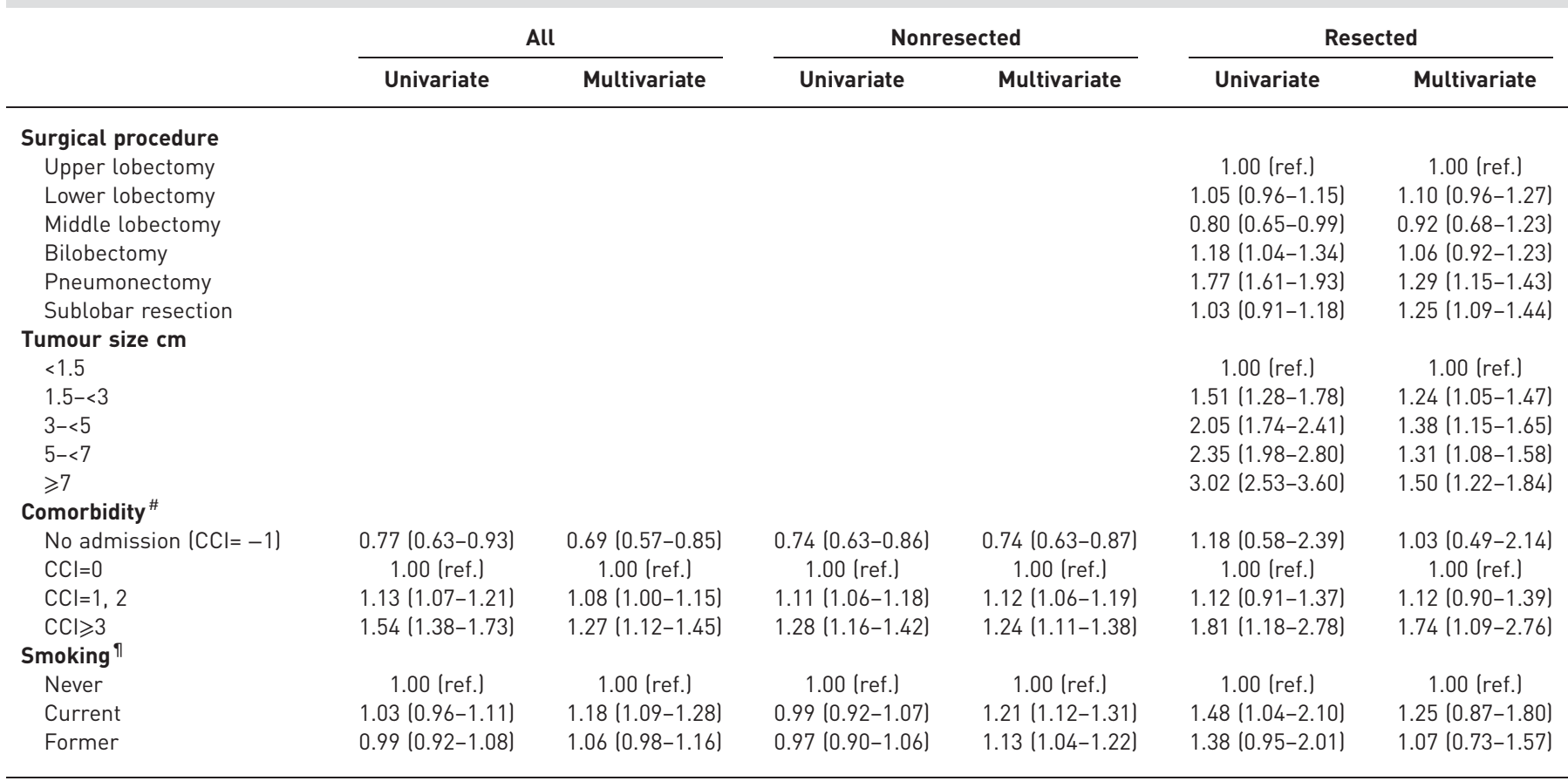

Data are presented as hazard ratio $(95 \% \mathrm{CI})$. ref.: reference value; NOS: not otherwise specified; pTNM: pathological tumour-node-metastasis; CCI: Charlson Comorbidity Index. " : patients diagnosed in 2009-2011, model includes all other covariates available in 1997-2011; П: patients diagnosed in 2004-2010, model includes all other covariates available in 1997-2011.

the resection rate stayed nearly constant, survival after resection improved, which may be explained partly by better selection of patients for surgery. Indeed, some patients that received resection in the past would now be considered unsuitable due to better diagnostic work-up and thus they contribute to lower the survival averages observed in the early periods. PET-CT will probably improve patient selection further in future and avoid futile thoracotomies.

Treatment for lung cancer has evolved substantially and resection has been gradually centralised [35]. In $2003,<20 \%$ were resected at a high-volume hospital, compared with $>80 \%$ in 2012 . Centralisation of surgery to high-volume or central hospitals may partly explain improved survival. Post-operative mortality in our study was lower in 2004-2011 compared with 1997-2003, which could be a reflection of improved surgical, anaesthetic and peri-operative care related to centralisation, and/or better patient selection resulting from improved diagnostic techniques. We believe that better diagnostic methods and improved peri-operative care also contributed.

The median waiting time for resection in our study was 26 days between 1998 and 2001. However, a steep increase in waiting time was observed after 2005, probably as a consequence of centralisation. In addition, more accurate diagnostic work-up demands more time-consuming examination, which can add to time before resection. However, this waiting time seems reasonable as it increases the likelihood that the correct patients receive resection and as, despite this waiting time, improved survival has been observed. The introduction of adjuvant chemotherapy towards the end of our study period might also explain better survival among our resected patients [4].

Stereotactic body radiotherapy was implemented in 2008 and may contribute to improved survival among nonresectable patients [36]. We were not able to stratify for regular and stereotactic radiotherapy. The prognosis among resected patients receiving adjuvant radiotherapy was inferior to that of resected patients not receiving adjuvant radiotherapy. This was expected as adjuvant radiotherapy after resection is often associated with not having free resection margins or more advanced disease than initially believed. A recent study from the CRN showed that only lung and breast cancers met national and international target levels for radiotherapy [21]. This is a good indication that the increased attention to lung cancer has led to improvements in care in Norway. Improved survival was seen among stage III nonsmall cell lung cancer patients treated with palliative radiotherapy in addition to chemotherapy, indicating that an improved, proactive attitude towards patients with an initial poor prognosis can be beneficial without reducing their quality of life [37]. 
TABLE 3 Comparison of hazard ratio for death within 1 year for different subgroups of explanatory variables between lung cancer patients diagnosed in 1997-2003 (reference) and 2004-2011 in Norway

\begin{tabular}{|c|c|c|c|}
\hline & All & Nonresected & Resected \\
\hline \multicolumn{4}{|l|}{ Age years } \\
\hline$<50$ & $0.78(0.67-0.92)$ & $0.81(0.69-0.95)$ & $0.54(0.30-1.00)$ \\
\hline $50-59$ & 0.77 (0.71-0.83) & $0.79(0.73-0.86)$ & $0.65(0.48-0.87)$ \\
\hline $60-69$ & $0.75(0.71-0.80)$ & $0.79(0.74-0.83)$ & $0.62(0.51-0.76)$ \\
\hline $70-79$ & $0.75(0.72-0.78)$ & $0.78(0.75-0.82)$ & $0.57(0.48-0.69)$ \\
\hline$\geqslant 80$ & 0.87 (0.82-0.93) & $0.92(0.87-0.99)$ & $0.34(0.21-0.55)$ \\
\hline \multicolumn{4}{|l|}{ Sex } \\
\hline Female & $0.77(0.73-0.80)$ & $0.81(0.77-0.85)$ & $0.58(0.47-0.71)$ \\
\hline Male & $0.78(0.75-0.81)$ & $0.81(0.78-0.84)$ & $0.60(0.52-0.69)$ \\
\hline \multicolumn{4}{|l|}{ Stage } \\
\hline Localised & $0.70(0.62-0.79)$ & $0.68(0.60-0.78)$ & $0.58(0.47-0.73)$ \\
\hline Regional & $0.79(0.74-0.84)$ & $0.80(0.75-0.86)$ & $0.61(0.52-0.72)$ \\
\hline Metastasis & $0.81(0.77-0.84)$ & $0.81(0.78-0.84)$ & $0.42(0.31-0.57)$ \\
\hline \multicolumn{4}{|l|}{ Education } \\
\hline Low & $0.77(0.74-0.81)$ & $0.81(0.78-0.85)$ & $0.59(0.50-0.69)$ \\
\hline Intermediate & $0.78(0.75-0.82)$ & $0.82(0.78-0.86)$ & $0.57(0.47-0.68)$ \\
\hline High & $0.74(0.67-0.82)$ & $0.78(0.71-0.87)$ & $0.70(0.46-1.04)$ \\
\hline \multicolumn{4}{|l|}{ Income } \\
\hline Low & $0.82(0.77-0.88)$ & $0.87(0.81-0.92)$ & $0.50(0.37-0.68)$ \\
\hline Intermediate & $0.76(0.73-0.79)$ & $0.80(0.77-0.83)$ & $0.59(0.51-0.68)$ \\
\hline High & $0.76(0.71-0.81)$ & $0.79(0.73-0.84)$ & $0.68(0.53-0.87)$ \\
\hline \multicolumn{4}{|l|}{ Topography } \\
\hline Main bronchus & $0.80(0.72-0.88)$ & $0.81(0.73-0.90)$ & $0.97(0.38-2.51)$ \\
\hline Upper lobe & $0.74(0.71-0.78)$ & $0.79(0.75-0.83)$ & $0.63(0.53-0.75)$ \\
\hline Middle lobe & $0.77(0.66-0.91)$ & $0.84(0.71-0.99)$ & $0.49(0.27-0.89)$ \\
\hline Lower lobe & $0.72(0.67-0.77)$ & $0.78(0.72-0.83)$ & $0.56(0.46-0.68)$ \\
\hline Overlapping lesion of lung & $0.74(0.56-0.97)$ & $0.80(0.60-1.07)$ & $0.49(0.22-1.10)$ \\
\hline Lung NOS & $0.81(0.77-0.85)$ & $0.83(0.79-0.87)$ & $0.79(0.44-1.42)$ \\
\hline \multicolumn{4}{|l|}{ Histology } \\
\hline Squamous cell carcinoma & $0.81(0.76-0.87)$ & $0.85(0.80-0.91)$ & $0.72(0.59-0.87)$ \\
\hline Adenocarcinoma & $0.70(0.66-0.73)$ & $0.75(0.71-0.79)$ & $0.49(0.42-0.59)$ \\
\hline Small cell carcinoma & $0.77(0.73-0.83)$ & $0.80(0.75-0.85)$ & $1.07(0.32-3.51)$ \\
\hline Large cell carcinoma & $0.90(0.80-1.02)$ & $0.97(0.86-1.10)$ & $0.52(0.35-0.77)$ \\
\hline Other specified carcinoma & $0.81(0.74-0.88)$ & $0.84(0.77-0.92)$ & $0.76(0.44-1.31)$ \\
\hline Carcinoma, not specified & $0.85(0.76-0.95)$ & $0.88(0.78-0.99)$ & $0.22(0.08-0.57)$ \\
\hline
\end{tabular}

Data are presented as hazard ratio $(95 \%$ CI). NOS: not otherwise specified. Estimates come from a multivariable analysis adjusting for the other available explanatory variables. Follow-up time for all patients and nonresected patients started at the date of diagnosis. Follow-up time among resected patients started at the date of resection.

All residents of Norway have equal access to healthcare regardless of social class. Despite this, higher education and income levels were associated with an increased resection rate. Furthermore, education was identified as an independent positive prognostic factor for survival. It can be speculated that these differences can be attributed to a higher prevalence of smoking among patients in the low socioeconomic group. As a consequence, these patients may have worse performance status and more advanced disease, which make them less likely to receive radical treatment. Our data on stage classification, comorbidity and smoking are imperfect, which can cause residual confounding on our estimates for the two socioeconomic status indicators. However, as previously stated, we identified comorbidity and smoking to be independent negative prognostic factors among all patients $[38,39]$.

Even though 1- and 5-year relative survival improved (figure 2), there was no statistically significant difference in the death rate for the third year when comparing survival in 1997-2003 and 2004-2011 (figure 3). This could indicate that the available surgical and oncological treatments only have a limited effect on long-term survival.

This study has some limitations. 1) We only included the first radiotherapy series, regardless of target. Furthermore, we used the target dose which was actually applied and not intended dose, which might cause some biased results as we were not able to determine those who received the completed dose from those 


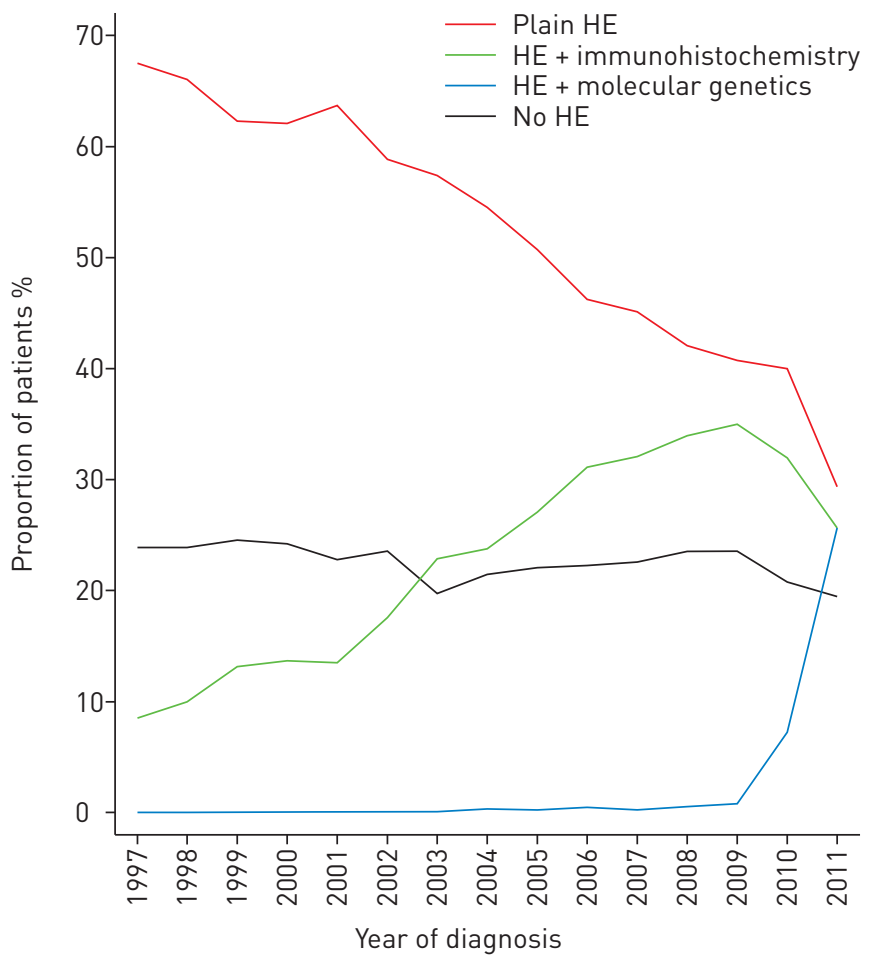

FIGURE 5 Time trend of basis for lung cancer diagnosis in Norway, 19972011 (n=34157). HE: histological examination (refers to no accompanying examination, such as molecular genetics or immunohistochemistry).

who underwent uncompleted radiotherapy. However, this bias is likely to be small as it only applies to $<6 \%$ of the patients, and the concordance between the given intention (radical or palliative) and the given dose for the other 94\% was high [21]. 2) Until 2008, stage was coded as unknown in the CRN if based solely on the pathology report (i.e. no valid clinical notification) and the report contained no information about metastases at the time of diagnosis. After 2008, these cases were coded as having localised disease if they received curative surgery. To avoid biased results we considered stage to be unknown for all patients after 2008 and used multiple imputation.

The present study also has some strengths: 1) complete information on resection and radiotherapy is a major advantage, and 2) the population-based study design and the use of national, comprehensive and high-quality data.

In conclusion, this study showed improvements in overall survival among resected and nonresected lung cancer patients in Norway between 1997 and 2011. The explanation for this appears to be multifactorial, including increased attention to lung cancer in general, thorough evaluation of patient health, more accurate diagnosis and improvements in treatment.

\section{References}

1 Hakulinen T, Engholm G, Gislum M, et al. Trends in the survival of patients diagnosed with cancers in the respiratory system in the Nordic countries 1964-2003 followed up to the end of 2006. Acta Oncol 2010; 49: 608-623.

2 Coleman MP, Forman D, Bryant H, et al. Cancer survival in Australia, Canada, Denmark, Norway, Sweden, and the UK, 1995-2007 (the International Cancer Benchmarking Partnership): an analysis of population-based cancer registry data. Lancet 2011; 377: 127-138.

3 De Angelis R, Sant M, Coleman MP, et al. Cancer survival in Europe 1999-2007 by country and age: results of EUROCARE-5 - a population-based study. Lancet Oncol 2014; 15: 23-34.

4 Arriagada R, Bergman B, Dunant A, et al. Cisplatin-based adjuvant chemotherapy in patients with completely resected non-small-cell lung cancer. N Engl J Med 2004; 350: 351-360.

5 Sagerup CM, Smastuen M, Johannesen TB, et al. Sex-specific trends in lung cancer incidence and survival: a population study of 40,118 cases. Thorax 2011; 66: 301-307.

6 Strand TE, Bartnes K, Rostad H. National trends in lung cancer surgery. Eur J Cardiothorac Surg 2012; 42: 355-358.

7 Birim O, Kappetein AP, van Klaveren RJ, et al. Prognostic factors in non-small cell lung cancer surgery. Eur J Surg Oncol 2006; 32: 12-23.

8 Powell HA, Tata LJ, Baldwin DR, et al. Early mortality after surgical resection for lung cancer: an analysis of the English National Lung cancer audit. Thorax 2013; 68: 826-834.

9 Radzikowska E, Glaz P, Roszkowski K. Lung cancer in women: age, smoking, histology, performance status, stage, initial treatment and survival. Population-based study of 20561 cases. Ann Oncol 2002; 13: 1087-1093. 
10 Forrest LF, White M, Rubin G, et al. The role of patient, tumour and system factors in socioeconomic inequalities in lung cancer treatment: population-based study. Br J Cancer 2014; 111: 608-618.

11 Sagerup CM, Smastuen M, Johannesen TB, et al. Increasing age and carcinoma not otherwise specified: a 20-year population study of 40,118 lung cancer patients. J Thorac Oncol 2012; 7: 57-63.

12 Chambers SK, Dunn J, Occhipinti S, et al. A systematic review of the impact of stigma and nihilism on lung cancer outcomes. BMC Cancer 2012; 12: 184.

13 Rostad H, Naalsund A, Norstein J, et al. Er behandlingen av lungekreft i Norge god nok [Is the treatment of lung cancer in Norway adequate?]. Tidsskr Nor Laegeforen 2002; 122: 2258-2262.

14 Bremnes RM, von Plessen C, Sundstrom S. Lungekreft - mer aktuelt enn noen gang [Lung cancer - of more current interest than before]. Tidsskr Nor Laegeforen 2006; 126: 1940.

15 Leira HO. Mye lungekreft - lite forskning [Much lung cancer - little research]. Tidsskr Nor Laegeforen 2014; 134: 2287-2288.

16 Larsen IK, Smastuen M, Johannesen TB, et al. Data quality at the Cancer Registry of Norway: an overview of comparability, completeness, validity and timeliness. Eur J Cancer 2009; 45: 1218-1231.

17 US Department of Health and Human Services. SEER program: comparative staging guide for cancer. Bethesda, US Department of Health and Human Services, 1993.

18 Sobin LH, Gospodarowicz MK, Wittekind C. TNM classification of malignant tumours. 7th Edn. Toronto, Wiley-Blackwell, 2009.

19 Parkin DM, Whelan SL, Ferlay J, et al. Cancer indidence in five continents, vol. VIII. Lyon, International Agency for Research on Cancer, 2002

20 Nilssen Y, Strand TE, Wiik R, et al. Utilizing national patient-register data to control for comorbidity in prognostic studies. Clin Epidemiol 2014; 6: 395-404.

21 Asli LM, Kvaloy SO, Jetne V, et al. Utilization of radiation therapy in Norway after the implementation of the national cancer plan - a national, population-based study. Int J Radiat Oncol Biol Phys 2014; 90: 707-714.

22 The Norwegian Directorate of Health. Nasjonalt handlingsprogram med retningslinjer for diagnostikk, behandling og oppfølgning av lungekreft [National guidelines for diagnosis and treatment of lung cancer]. Oslo, The Norwegian Directorate of Health, 2014.

23 White IR, Royston P, Wood AM. Multiple imputation using chained equations: issues and guidance for practice. Stat Med 2011; 30: 377-399.

24 StataCorp. Stata statistical software: release 13. College Station, StataCorp, 2013.

25 Pohar-Perme MP, Stare J, Esteve J. On estimation in relative survival. Biometrics 2012; 68: 113-120.

26 Brenner H, Rachet B. Hybrid analysis for up-to-date long-term survival rates in cancer registries with delayed recording of incident cases. Eur I Cancer 2004; 40: 2494-2501.

27 Allemani C, Weir HK, Carreira H, et al. Global surveillance of cancer survival 1995-2009: analysis of individual data for 25,676,887 patients from 279 population-based registries in 67 countries (CONCORD-2). Lancet 2015; 385: 977-1010.

28 Aarts MJ, van den Borne BE, Biesma B, et al. Improvement in population-based survival of stage IV NSCLC due to increased use of chemotherapy. Int J Cancer 2015; 136: E387-E395.

29 Bowen EF, Anderson JR, Roddie ME. Improving surgical resection rates in lung cancer without a two stop service. Thorax 2003; 58: 368.

30 Mok TS, Wu YL, Thongprasert S, et al. Gefitinib or carboplatin-paclitaxel in pulmonary adenocarcinoma. $N$ Engl J Med 2009; 361: 947-957.

31 Brustugun OT, Helland A, Fjellbirkeland L, et al. Mutasjonstesting ved ikke-småcellet lungekreft [Mutation testing for non-small-cell lung cancer]. Tidsskr Nor Laegeforen 2012; 132: 952-955.

32 Sandelin M, Berglund A, Sundstrom M, et al. Patients with non-small cell lung cancer analyzed for EGFR: adherence to guidelines, prevalence and outcome. Anticancer Res 2015; 35: 3979-3985.

33 Norwegian Radiation Protection Authority. Radiologiske undersokelser i Norge per 2008 [Radiological investigations in Norway 2008]. Oslo, Norwegian Radiation Protection Authority, 2010.

34 Hicks RJ, Kalff V, MacManus MP, et al. ${ }^{18}$ F-FDG PET provides high-impact and powerful prognostic stratification in staging newly diagnosed non-small cell lung cancer. J Nucl Med 2001; 42: 1596-1604

35 Norwegian Lung Cancer Registry. Årsrapport [Annual report]. Oslo, Cancer Registry of Norway, 2014.

36 Matsuo Y, Chen F, Hamaji M, et al. Comparison of long-term survival outcomes between stereotactic body radiotherapy and sublobar resection for stage I non-small-cell lung cancer in patients at high risk for lobectomy: a propensity score matching analysis. Eur J Cancer 2014; 50: 2932-2938.

37 Strom HH, Bremnes RM, Sundstrom SH, et al. Concurrent palliative chemoradiation leads to survival and quality of life benefits in poor prognosis stage III non-small-cell lung cancer: a randomised trial by the Norwegian Lung Cancer Study Group. Br J Cancer 2013; 109: 1467-1475.

38 Deleuran T, Thomsen RW, Norgaard M, Jacobsen JB, Rasmussen TR, Sogaard M. Comorbidity and survival of Danish lung cancer patients from 2000-2011: a population-based cohort study. Clin Epidemiol 2013; 5: Suppl. 1, 31-38.

39 Kogure Y, Ando M, Saka H, et al. Histology and smoking status predict survival of patients with advanced non-small-cell lung cancer. Results of West Japan Oncology Group (WJOG) Study 3906L. J Thorac Oncol 2013; 8: 753-758. 